\title{
Um Agente de Interface Aplicado ao Ensino de Equações de Primeiro Grau
}

\author{
Roberto dos Santos Rabello ${ }^{1}$ \\ Eliseo Reategui ${ }^{2}$ \\ Julio César Giordani Costi ${ }^{3}$ \\ ${ }^{1}$ Doutorando em Informática Aplicada a Educação - PGIE - Universidade Federal do \\ Rio Grande do Sul - Porto Alegre - RS - Brasil \\ Roberto.rabello@ufrgs.br \\ ${ }^{2}$ Doutor em Ciência da Computação. Departamento de Informática - Universidade de \\ Caxias do Sul - Caxias do Sul RS \\ eliseoreateguiegmail.com \\ ${ }^{3}$ Bacharel em Ciência da Computação - Universidade de Passo Fundo - Passo Fundo - \\ RS - Brasil \\ jcosti82@yahoo.com. br
}

\begin{abstract}
Resumo. Agentes inteligentes podem ser considerados uma tecnologia relativamente nova que tem-se destacado como um elemento importante no desenvolvimento de softwares com interfaces interativas. Tais interfaces combinam elementos como afetividade, animações e imagens visando melhorar a construção do conhecimento através do uso destes softwares. $O$ objetivo deste artigo é justamente demonstrar como os agentes de interface podem ser utilizados para aumentar o grau de interatividade com os estudantes e produzir resultados positivos nos processos de aprendizagem.
\end{abstract}

Palavras Chave: Agentes, interatividade, interface

\begin{abstract}
Intelligent agents can be considered a relatively new technology which has been used as an important element in the development of software with interactive interfaces. Such interfaces combine elements as affectivity, animation and imagery in order to improve learning through the use of the software. The goal of this article is to demonstrate how the interface agents may be used to improve the interaction with students and produce positive results in learning processes.
\end{abstract}

Keywords: Agents, Interactivity, interface

Os recursos e técnicas de desenvolvimento de softwares educacionais estão cada vez mais aprimorados. Porém, em alguns casos, tantos recursos são utilizados que acabam levando a uma sobrecarga cognitiva. De acordo com Precce (2005), cognição é o que acontece em nossas mentes quando realizamos nossas tarefas diárias; envolve processos cognitivos, tais como pensar, lembrar, aprender, fantasiar, tomar decisões, ver, ler, escrever e falar. No caso da instrução baseada por computador ou da instrução baseada na web, exige-se um esforço mental excessivo para acessar e interpretar as telas, ícones e objetos, como o processo cognitivo dedicado para processar o real conteúdo da instrução. Este artigo descreve os agentes de interface e mostra como foram aplicados 
em um software para ensino de equações do primeiro grau. $\mathrm{O}$ artigo apresenta uma breve introdução sobre agentes inteligentes, agentes de interface e na sequiência descreve como esta tecnologia contribuiu para o desenvolvimento de um software com maior interatividade auxiliando o aprendizado da matemática.

\section{Agentes Inteligentes}

Agente nada mais é que um elemento autônomo que representa, manipula, troca informações e conhecimento dependendo de um determinado espaço. Segundo Russel e Norvig, "um agente é tudo o que pode ser considerado capaz de perceber seu ambiente por meio de sensores e de agir sobre esse ambiente por intermédio de atuadores."(2004, p.33).

A figura 1 ilustra melhor essa definição. Os sensores seriam, por exemplo, os ouvidos e outros órgãos de um ser humano e os atuadores poderiam ser os pés e outras partes do corpo de uma pessoa. A respeito do termo percepções, pode-se pensar nas entradas percebidas e as ações como a escolha que o agente fará baseado nas percepções. A esta figura também cabe o conceito apresentado por Coelho (1995, p.415), que afirma que um agente inteligente reside na relação entre os seus estados mentais e o ambiente onde está inserido.

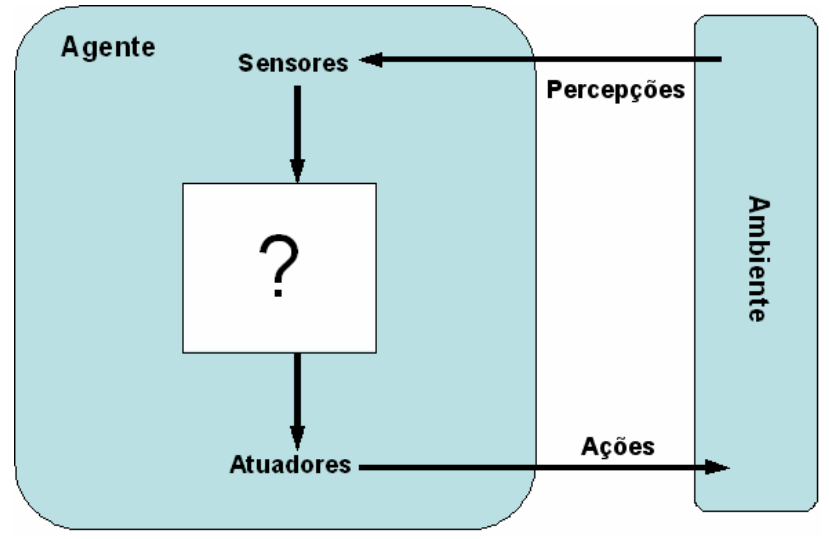

Fonte: Adaptado de Russel e Norvig, 2004, p.34.

Figura 1 - Agentes interagem com ambientes por meio de sensores e atuadores -

Ainda neste contexto, "agentes são sistemas computacionais capazes de ações autônomas em algum ambiente, a fim de alcançar seus objetivos de projeto." (WOOLDRIDGE apud SCHWAMBACH, 2004, p.7). O agente tem a capacidade de realizar ações autônomas flexíveis com reatividade, pró-atividade e habilidade social.

Analisa-se neste contexto também a definição de Agente Racional que, segundo Russel e Norvig, "é aquele que faz tudo certo" (2004, p.35). Para que um agente possa ser considerado racional deve-se levar em conta questões do ambiente em que ele atua e seus sensores e atuadores, como também a tarefa que o mesmo deverá empregar. É importante também ressaltar que uma medida objetiva (uma boa medida de desempenho) deverá ser imposta pelo projetista que constrói o agente. Todos os agentes podem melhorar seu desempenho por meio do aprendizado de determinadas funções. 
Segundo Schwambachv (2004, p.8), existe uma divisão inicial dos agentes em reativos e cognitivos. Agentes reativos não usam um raciocínio simbólico completo, não possuem estruturas de memória complexas e uma forma de representação interna explicita do conhecimento. Já os agentes cognitivos são capazes de raciocinar a respeito de determinadas intenções e conhecimentos, criar planos de ação e realizar sua execução.

Pode-se definir um agente inteligente como uma entidade que executa um conjunto de operações que lhes foram impostas por um usuário ou programa, sendo que deve ter certo grau de autonomia ou independência, executando as operações necessárias empregando algum conhecimento dos objetivos ou desejos do usuário. Portanto três elementos definem as capacidades que um agente inteligente deve empregar a seu funcionamento, ou seja, inteligência (grau de raciocino e aprendizagem) agência (autonomia e autoridade incorporadas), mobilidade (capacidade de tráfego pela rede).

Assim sendo, temos "os sistemas multiagentes (SMAs), que são sistemas computacionais compostos por diversos agentes interagindo no ambiente a fim de alcançar seus objetivos de projeto. Em um SMA, agentes precisam se comunicar a fim de alcançar melhor seus objetivos ou os objetivos do sistema/sociedade no qual eles existem." (SCHWAMBACHV, 2004, p.8). Estes sistemas multiagentes e os agentes em si são uma preocupação para a área de engenharia de software, que trabalha com a questão de como desenvolver sistemas que atendam realmente as necessidades do ambiente.

Todas estas definições até aqui expostas foram apresentadas para que se possa entender melhor os conceitos de agentes inteligentes e consequentemente entender na sequiência o que são os agentes de interface e suas funcionalidades. A figura 2 mostra quais são as categorias dos agentes inteligentes, dentre elas destacam-se os agentes de interface, objeto de investigação deste trabalho.

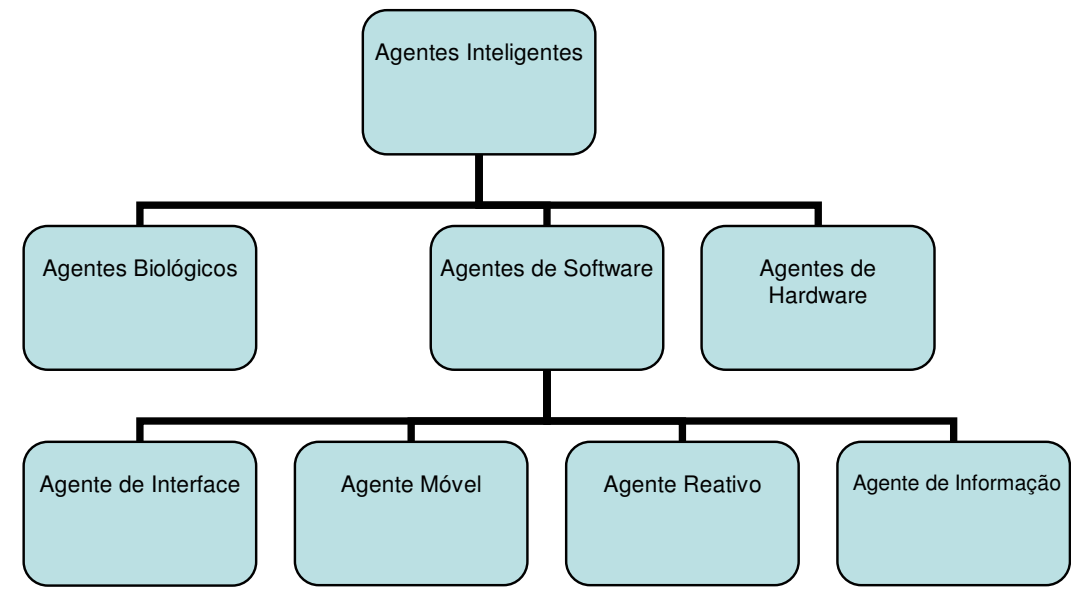

Fonte: Adaptado de Brener,1998.

Figura 2 - Categorias de Agentes Inteligentes

\section{Agentes de Interface}

Os agentes de interface são conhecidos como assistentes que ficam rodando em background, analisando as ações dos usuários tanto para auxiliá-los quanto para executar ações em seu lugar, sempre analisando os padrões de ação do usuário para automatizá-los. Normalmente estes agentes têm a função de dar apoio à utilização de uma aplicação em particular. $\mathrm{O}$ agente fica observando a utilização do software, e 
sugerindo maneiras melhores de executar as tarefas. Assim, conforme Nwana (1996), o agente atua como um assistente pessoal autônomo que coopera com o usuário realizando algumas tarefas na aplicação. Estes componentes de software podem ou não ter uma forma de visualização gráfica. Quando isso ocorre, são normalmente chamados de agentes de interface animados, ou agentes de interface personificados. Neste artigo, nosso objeto de estudo são justamente estes agentes representados graficamente por personagens animados.

Os agentes de interface aprendem para oferecer um melhor auxílio aos seus usuários. Segundo Maes (1994), os agentes de interface podem aprender a partir de quatro maneiras:

- Observando e imitando o usuário (aprendendo a partir do usuário).

- Recebendo do usuário retorno positivo e negativo (aprendendo a partir do usuário).

- Recebendo instruções explícitas do usuário (aprendendo a partir do usuário).

- Solicitando orientação para outros agentes (aprendendo a partir de parceiros).

Um exemplo muito comum de agente de interface animado é o Clip do Microsoft Word, que fica rodando de forma oculta até o momento que percebe uma necessidade do usuário e, de forma autônoma, se manifesta oferecendo ajuda.

Os agentes de Interface possuem papéis importantes de conselheiro, guia e facilitador. Mas para que estas funções sejam efetivadas, outra característica é fundamental para dar credibilidade ao usuário, que é a presença de afetividade. O uso da afetividade na computação, de acordo com Piccard (1997), implica na utilização das emoções em diferentes aspectos nos sistemas, desde o controle até a personalização de interfaces, da simulação de sistemas com emoções à representação de emoções, do estudo das emoções através de sistemas até pesquisas que envolvem emoções nas interações Homem-Máquina. Essa participação da afetividade na IHC nos leva ao conceito de agentes emocionais, ou seja, agentes inteligentes que possuem características de afetividade (Preece, 2005). Para Berch (2001) o termo mais adequado para agentes com emoções é agentes afetivos, que são utilizados para designá-los quando possuem habilidades associadas com emoções, sem perder a capacidade de realizar raciocínios puramente intelectuais. Estas características dos agentes, levam ao conceito de Sistemas Afetivos, que são sistemas desenvolvidos com algumas das capacidades de reconhecer, expressar, possuir ou desenvolver emoções.

Ao desenvolver agentes de interface com a presença de afetividade, algumas questões são levantadas, como por exemplo: Como se projetar agentes e personagens virtuais e torná-los convincentes? Ou seja, como fazer com que o usuário acredite que os agentes possuem suas próprias crenças, desejos e intenções? Um aspecto importante é combinar a personalidade e o humor do personagem a suas ações como pular, sorrir e chorar para os diferentes tipos de emoções e humores. Como uma expressão "muito feliz" pode ser reproduzida? Com um personagem exibindo um sorriso escancarado na face? E o quão fácil é para o usuário diferenciar o estereotipo de "muito feliz" e "feliz", ou seja, como medir a intensidade emocional reproduzida por uma expressão?

De acordo com pesquisas recentes as pessoas tendem a preferir personagens simples baseados em desenhos animados a imagens detalhadas que tentam parecer o máximo possível com formas humanas (Preece, 2005),. Um projeto realizado por 
pesquisadores da Apple Computer inc. nos anos 80 descobriu que as pessoas reagiam de forma distinta a diferentes representações do mesmo agente de interface. O agente em questão, chamado Phill (Nwana, 1996), foi criado utilizando duas formas de representação: um personagem tinha a fisionomia idêntica de um ser humano, o outro era representado por um desenho do mesmo ator. A pesquisa realizada demonstrou que a segunda forma de representação foi muito mais apreciada pelos usuários do sistema.

Outra consideração importante ao se criar agentes de interface é o comportamento dos mesmos. Ou seja, é fundamental que eles tenham sincronia entre seus estados emocionais internos e seus movimentos ou expressões. Caso se espere que o agente esteja feliz, a postura do corpo, os movimentos e a expressão facial precisam estar integrados e demonstrar isso.

A forma como o agente interage com o usuário também é importante para que ele seja convincente. Para demonstrar um comportamento inteligente, é possível empregar técnicas de processamento de linguagem natural, permitindo que este "converse" com o usuário através da linguagem falada. Outra possibilidade é projetar um agente que não procure demonstrar um nível de inteligência tão alto, sendo possível neste caso fazer com que o agente opere apenas como um auxiliar, respondendo questões somente quando for chamado para intervir.

\section{O Agente Pepe}

A partir dos conceitos de agentes de interface apresentados anteriormente, um sistema aplicado ao ensino de equações do primeiro grau foi desenvolvido,utilizando os agentes animados da Microsoft (Costi, 2005). No sistema foi definida uma sociedade de quatro agentes, cada um possuindo funções específicas, de acordo com o modelo ilustrado na figura 3 .

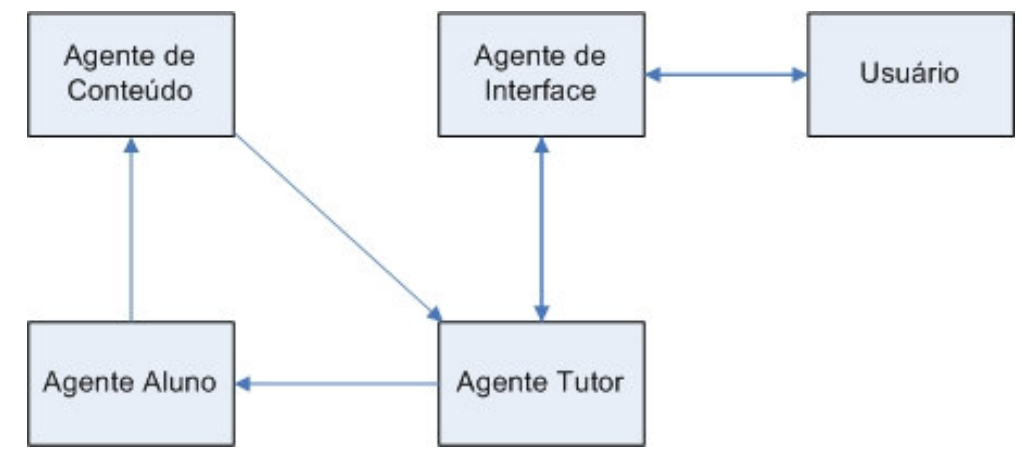

Figura 3 - Estrutura dos agentes

$\mathrm{O}$ agente de interface tem por função auxiliar o usuário quanto ao uso do sistema, assistindo-o e respondendo a comandos específicos. O agente também provê ajuda quando o usuário passa certo tempo em alguma tela, aparentemente sem saber o que fazer, ou quando for solicitada por ele espontaneamente. Basicamente mostra-se uma mensagem de auxílio de acordo com uma ação do usuário. Trata-se portanto de um agente reativo que toma decisões conforme uma necessidade momentânea e não se baseia em um modelo mais complexo das ações do usuário.

Em relação à interface com o estudante, sabe-se que as mensagens devem ser agradáveis, claras e intuitivas (Alcantara, 2004). Os recursos dos agentes animados da 
Microsoft se mostram uma boa alternativa para prover formas de interação mais atrativas e, porque não, divertidas.

No sistema proposto, são usados personagens com as mais variadas ações no que se refere à comunicação com o usuário. Estes podem atuar dando as boas vindas ao usuário, apresentar dicas e diálogos pertinentes através de recursos escritos e orais. Estes agentes representam o componente interativo do sistema tutor inteligente.

Quatro personagens são disponibilizados para o usuário: Pepe (papagaio), Merlin (mago), Jonas (gênio da lâmpada) e Bob (robô), podendo ser selecionados de acordo com sua preferência.
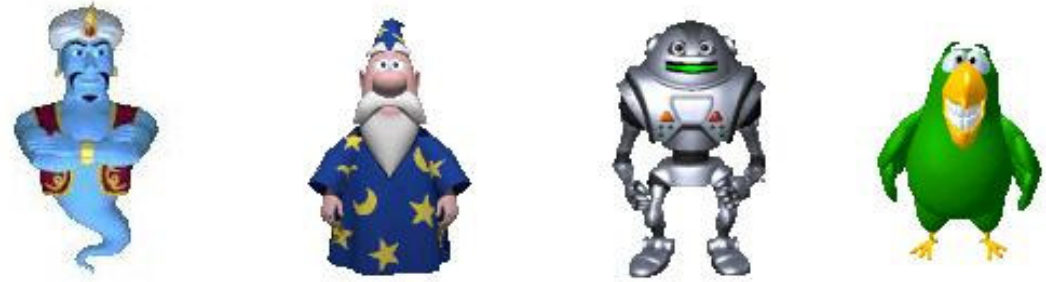

Figura 4 - Atores

A figura 5 mostra um diálogo apresentado ao usuário pelo agente Pepe.

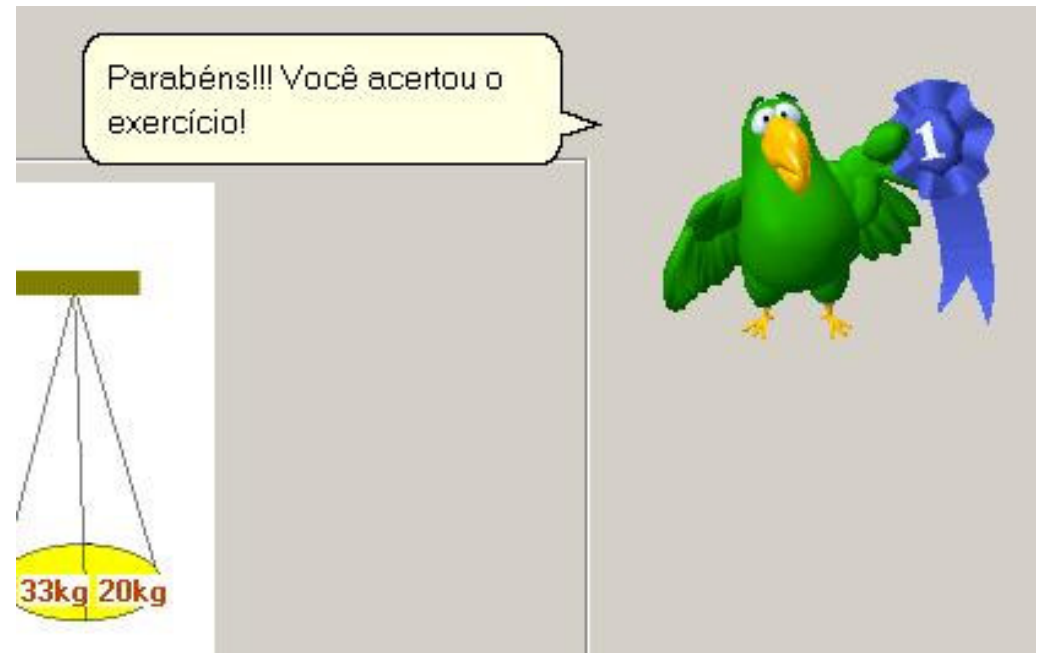

Figura 5 - Pepe congratulando o aluno

O aluno pode escolher o personagem que desejar, e trocá-lo sempre que desejar. Além do mais, o aluno pode alterar a frequiência da voz do seu ator escolhido. Isso visa evitar que a comunicação por meio do personagem torne-se aborrecedora.

A utilização destes personagens ainda leva em conta as seguintes características:

- Não são empregadas figuras humanas reais para não passar ao estudante a idéia de que o personagem cumpre o papel de um professor comportamentalista que tradicionalmente ministra as aulas.

- Além de gesticular, falar, pensar e expressar alguns sentimentos, os personagens movem-se pelo ambiente. 
- Os personagens dão um ar descontraído ao sistema de aprendizagem, chamando a atenção do aluno e motivando-o na realização das tarefas.

Os agentes, além de interagirem com o usuário na forma de tutoria, também podem se manifestar de modo autônomo caso o aluno cometa algum erro, como pode ser visualizado na figura 6.

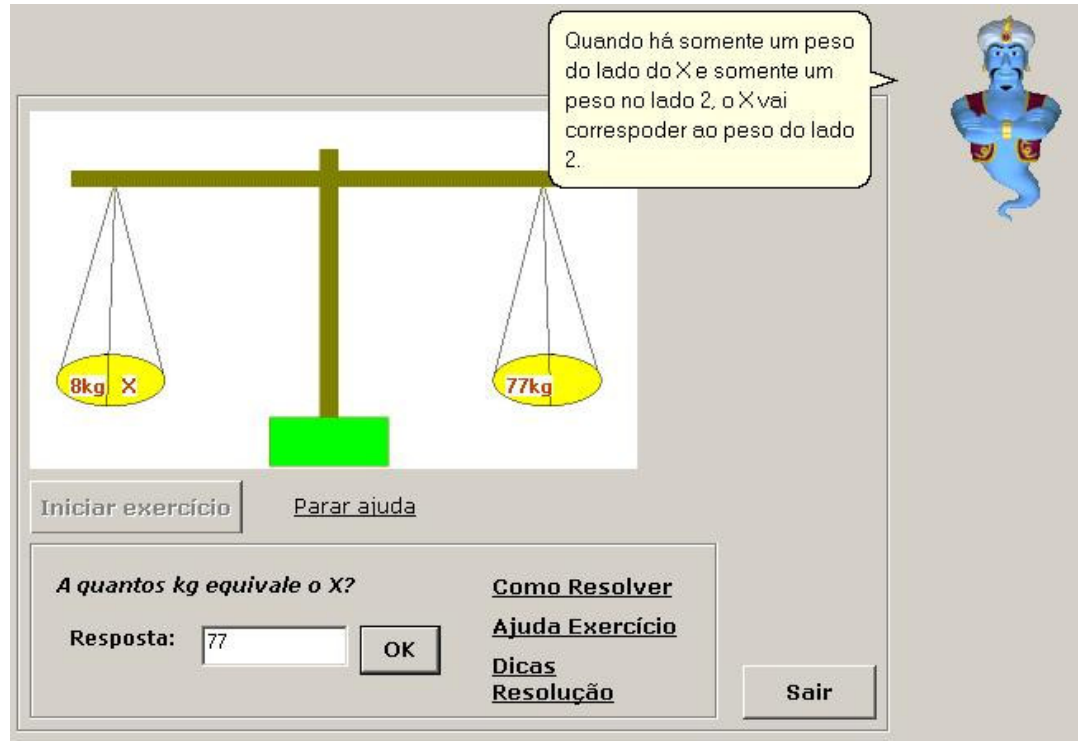

Figura 6 - Exemplo de ajuda de contexto

O sistema ainda possui ainda um módulo no qual o agente conduz o aluno (figura 7), mostrando um diálogo de ajuda sobre o exercício sendo realizado. Já na primeira tentativa, se o aluno errar, o agente intervém mostrando a resolução do exercício passo a passo. No exemplo, o tutor mostra a lei da seqüência para o aluno, explicando que ele deve aplicar essa fórmula sobre o último termo para encontrar o termo seguinte.

No modo interativo, o agente tutor intervém revisando o exercício depois que o aluno não teve sucesso em uma segunda tentativa, ou quando o aluno solicita a ajuda clicando no link "Ajuda Exercício". As dicas visam dar uma idéia para o aluno de como resolver os problemas, baseando-se nos primeiros termos da seqüência. Em ambos os modos, como no exercício da balança, após responder um exercício, o aluno vê o diálogo pertinente no momento. Após acertar ou exceder três tentativas, o estudante deve pressionar um botão para ir ao próximo exercício, ou sair do exercício, voltando à tela inicial. 


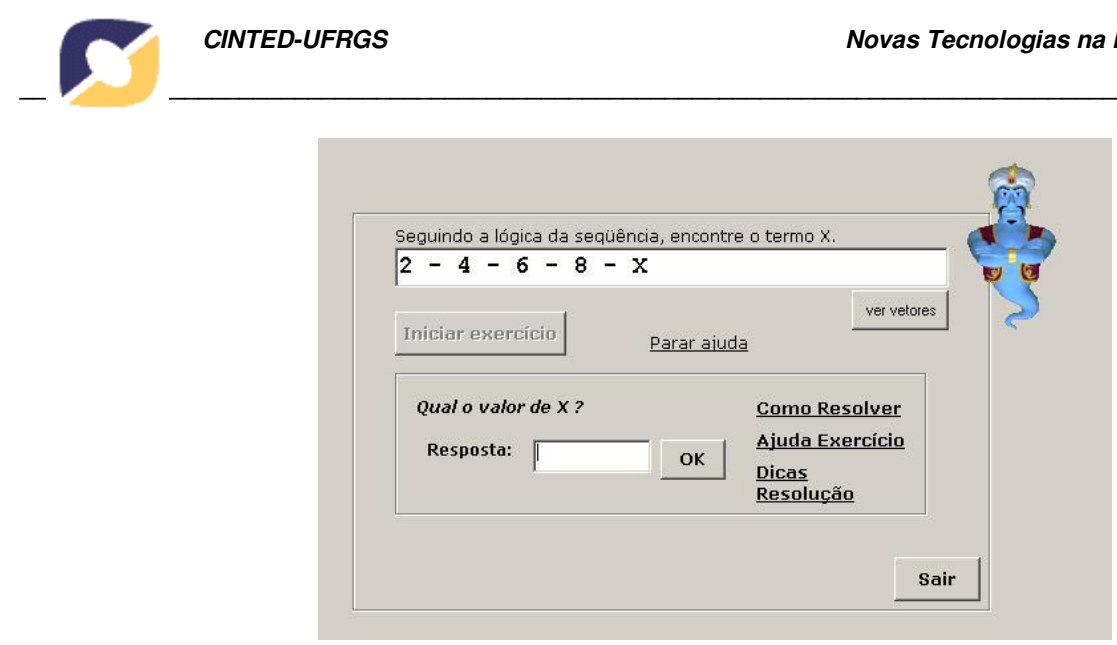

Figura 7 - Exercício da seqüência de termos

Para validar a pesquisa foi considerada uma amostragem de sete alunos da quinta série, de ambos os sexos, da Escola de Ensino Fundamental Jardim América, localizada em Passo Fundo - RS.

O protótipo de STI foi instalado em sete computadores do laboratório central de informática da Universidade de Passo Fundo (UPF). Como os alunos nunca haviam utilizado o software, foram dadas orientações básicas sobre como proceder para resolver os exercícios e as tarefas que deveriam desenvolver, e então foi deixado que usassem o protótipo durante 45 minutos. Ao final deste tempo foi aplicado aos alunos um questionário com perguntas relacionadas a interface e aos agentes utilizados. Os entrevistados reiteraram a importância da ajuda dos agentes na compreensão da utilização do software e da resolução dos exercícios. Todos os alunos entrevistados acharam importante a intervenção dos agentes e um aluno inclusive respondeu que não conseguiria resolver os exercícios sem esse auxilio. Mesmo com a possibilidade de desabilitar esta ajuda, nenhum aluno solicitou tal procedimento. Além da aplicação do questionário, foi observada a atitude dos alunos ao utilizar o software e foi identificado que dois alunos inicialmente ignoravam os agentes, mas ao observar que os colegas estavam avançando as fases com maior facilidade utilizando os agentes, acabaram ficando atentos as suas intervenções.

O software armazena na sua base de conhecimento informações sobre as atividades realizadas pelo aluno e orienta em que fase ele deve jogar, pois avançar de fase sem ter cumprido as fases anteriores poderá frustá-los ao não conseguir resolver os exercícios. Além disso, os agentes intervêm se o aluno ficar muito tempo sem realizar alguma ação, identificando assim que ele está pensando, mas não está conseguindo resolver as atividades. O software ainda possui um módulo que auxilia "como fazer", dicas, ajuda e ainda os procedimentos para resolução de cada exercício. Ainda possui um agente de tutoria que auxilia passo a passo a resolução das atividades, além de um agente que ao perceber a dificuldade do usuário intercede falando sobre o conteúdo utilizado no exercício. Estes objetos são chamados de agentes tutores e agentes de conteúdo, respectivamente. Os recursos multimídia combinados com uma base de conhecimento para identificação do perfil e aspectos de autonomia dos agentes permitiram que a avaliação da utilização do software fosse positiva. 


\section{Considerações finais}

Novas tecnologias estão sempre surgindo e mais uma vez isto é comprovado através dos agentes que trouxeram um novo desafio ao desenvolvimento de softwares educacionais. Ao mesmo tempo em que as novas tecnologias vieram para ajudar, sabe-se que o abuso do uso de recursos como cores, imagens, vídeos e animações, pode comprometer a usabilidade e os resultados esperados. No protótipo desenvolvido com a finalidade de auxiliar os alunos do ensino fundamental no aprendizado de equações do primeiro grau, detectou-se uma afinidade muito grande das crianças que utilizaram o software com os agentes de interface. Os agentes identificam quais as dificuldades dos alunos e ajustam suas ações auxiliando-os tanto na forma de tutoria como de correção dos exercícios propostos. Apesar de essa autonomia poder ser desabilitada pelo próprio usuário, nenhum aluno escolheu essa opção. Apenas um detalhe originou alguns resultados negativos: o uso do som para fazer a leitura das informações apresentadas textualmente aos usuário fez com que os alunos se tornassem intolerantes à interação com os agentes, queixando-se da voz robotizada dos personagens. Mesmo assim, comprova-se a importância das interfaces interativas para o desenvolvimento de softwares educacionais, mostrando que os agentes de interface têm um papel importante neste contexto.

\section{Referências}

ALCANTARA, Igor Raphael. Microsoft Agents: Tornando a interação com o usuário mais divertida. 2004. Disponível em: $<$ http://www.neoficio.com.br/msdn/colunistas/igorAlcantara/01_MicrosoftAgents.asp $>$. Acessado em: 27 nov. 2005.

BERCH, Magda. Em direção a agentes pedagógicos com dimensões afetivas. Tese (Doutorado em Ciência da Computação) - Instituto de Informática, UFRGS, Porto Alegre, 2001.

COELHO, Helder. Inteligência Artificial em 25 lições. 1.ed. : Fundação Calouste Gulbinkian, 1995.

COSTI, Julio César Giordani. Desenvolvimento do protótipo de um sistema tutor inteligente aplicado ao ensino de equações do primeiro grau. Trabalho de Conclusão de Curso (Ciência da Computação), Universidade de Passo Fundo, Passo Fundo, 2006. Orientado pelo professor Roberto dos Santos Rabello.

Maes, P. Agents that Reduce Work and Information Overload. Communications of the ACM, Vol. 37, No. 7, pp.31-40, July 1994.

Nwana, H. Software Agents: An Overview. Knowledge Engineering Review, Vol. 11, N. 3, pp. 1-40, September 1996.

PFLEEGER, Shari Lawrence. Engenharia de Software: Teoria e Prática. 2.ed. São Paulo: Prentice Hall, 2004.

Preece, J., Rogers, Y., Sharp, H. (2005) Design de Interação: Além da Interação Humano-Computador. Porto Alegre, RS. Bookman. 
RUSSEL, Stuart; NORVIG, Peter. Inteligência Artificial. Tradução 2.ed. Rio de Janeiro: Campus, 2004.

SCHWAMBACH, Mellyssa De Martins. Uma metodologia para desenvolvimento de sistemas baseados em agentes e objetos. Dissertação (Mestrado em Informática) Departamento de Informática, Universidade Federal do Espírito Santo, Vitória, 2004.

SOMMERVILLE, Ian. Engenharia de Software. 6.ed. São Paulo: Pearson Education do Brasil,2003. 